\title{
Fear of Cancer Recurrence and Disease Progression in Long-Term Prostate Cancer Survivors After Radical Prostatectomy: A Longitudinal Study
}

\author{
Valentin H. Meissner, MD (ID 1; Lisa Olze, MD'; Stefan Schiele, MSc'; Donna P. Ankerst, PhD²; Matthias Jahnen, MD (iD) 1; \\ Jürgen E. Gschwend, MD'; Kathleen Herkommer, MD, MBA'; and Andreas Dinkel, DSc (iD 3
}

\begin{abstract}
BACKGROUND: Although fear of cancer recurrence (FCR) or disease progression is among the most endorsed unmet needs and concerns of cancer survivors, research on the course of FCR in long-term survivors is scarce. The objective of this study was to assess longitudinally the prevalence and predictors of FCR in long-term prostate cancer (PCa) survivors. METHODS: In all, 2417 survivors from the multicenter German Familial Prostate Cancer Database completed the Fear of Progression Questionnaire-Short Form on average 7 years (T1 in 2010) after radical prostatectomy and at follow-up 9 years later (T2 in 2019). Hierarchical multivariable logistic regression was used to assess predictors of FCR at follow-up. RESULTS: The mean age at the initial assessment was 69.5 years (standard deviation, 5.9 years); $6.5 \%$ and $8.4 \%$ of patients reported clinical FCR at the initial assessment (T1) and at the follow-up (T2), respectively. In a multivariable analysis controlling for concurrent associations, longitudinal predictors of FCR 9 years later included a lower level of education (odds ratio [OR], 4.35; 95\% confidence interval [Cl], 2.33-8.33), years since radical prostatectomy (OR, 1.10; 95\% $\mathrm{Cl}, 1.03-1.18$ ), biochemical recurrence (OR, 1.67; 95\% Cl, 1.02-2.72), no current adjuvant therapy (OR, 2.38; 95\% Cl, 1.19-4.76), $\mathrm{FCR}(\mathrm{OR}, 10.75 ; 95 \% \mathrm{Cl}$, 6.18-18.72), and anxiety (OR, 1.35; 95\% Cl, 1.06-1.72). CONCLUSIONS: FCR remains a burden to certain PCa survivors even many years after their diagnosis and treatment. Health care professionals should monitor for FCR and identify patients at risk to provide appropriate psychosocial care because FCR is leading to limitations in quality of life and psychological well-being. Cancer 2021;127:4287-4295. (c) 2021 The Authors. Cancer published by Wiley Periodicals LLC on behalf of American Cancer Society This is an open access article under the terms of the Creative Commons Attribution-NonCommercial-NoDerivs License, which permits use and distribution in any medium, provided the original work is properly cited, the use is non-commercial and no modifications or adaptations are made.
\end{abstract}

KEYWORDS: fear of cancer recurrence, longitudinal study, prostate cancer, radical prostatectomy, survivorship.

\section{INTRODUCTION}

Prostate cancer $(\mathrm{PCa})$ is the second most frequently diagnosed cancer in men in the United States and Europe. ${ }^{1,2}$ In light of high survival rates that translate PCa survivorship into a long-lived experience, improvements in quality of life (QOL) and psychological well-being are fundamental considerations in care after diagnosis and treatment. Recent research has shown that fear of cancer recurrence (FCR) or disease progression is among the most commonly endorsed unmet needs and concerns in cancer survivors, and it is frequently accompanied by a clinically significant impact on QOL. ${ }^{3-5}$ FCR has been defined as "fear, worry, or concern about cancer returning or progressing," and such fears can arise at diagnosis and continue throughout the survivorship trajectory. ${ }^{6} \mathrm{~A}$ moderate amount of FCR has been found to promote adequate screening uptake, whereas too little or too much FCR can lead to avoidance of screening uptake and maintenance to identify recurrence in a timely fashion. ${ }^{7,8}$

A longitudinal study of 519 patients with PCa found a significant decline in FCR after treatment followed by stable levels over the subsequent 2 years. ${ }^{9}$ A cross-sectional study in long-term PCa survivors with a median postsurgery follow-up of 7.1 years found that a third still suffered from high levels of FCR, with younger age, lower QOL, distress, and the receipt of adjuvant radiotherapy being associated with high FCR. ${ }^{10}$

To date, previous research on FCR in PCa survivors has mostly focused on short-term follow-up care after diagnosis and treatment. Longitudinal studies examining risk factors for long-term FCR in PCa survivors surviving

Corresponding Author: Valentin H. Meissner, MD, Department of Urology, Klinikum rechts der Isar, School of Medicine, Technical University of Munich, Ismaninger Strasse 22, 81675 Munich, Germany (valentin.meissner@tum.de).

${ }^{1}$ Department of Urology, Klinikum rechts der Isar, School of Medicine, Technical University of Munich, Munich, Germany; ${ }^{2}$ Departments of Mathematics and Life Science Systems, Technical University of Munich, Garching, Germany; ${ }^{3}$ Department of Psychosomatic Medicine and Psychotherapy, Klinikum rechts der Isar, School of Medicine, Technical University of Munich, Munich, Germany

See editorial on pages 4140-4141, this issue.

Additional supporting information may be found in the online version of this article.

DOI: 10.1002/cncr.33836, Received: November 29, 2020; Revised: April 8, 2021; Accepted: May 3, 2021, Published online August 6, 2021 in Wiley Online Library (wileyonlinelibrary.com) 
decades and more because of improved treatment are needed to improve patient management, surveillance, and psychological care. Thus, on the basis of a large sample of long-term PCa survivors after radical prostatectomy (RP), the objectives of this study were to 1 ) assess the prevalence of FCR, 2) prospectively evaluate changes in the trajectory of FCR over a 9-year period, and 3) identify and assess predictors of high FCR in long-term PCa survivors.

\section{MATERIALS AND METHODS}

\section{Database and Study Procedure}

The current analysis is based on data from the multicenter German Familial Prostate Cancer Database, which comprises more than 36,000 index patients and their relatives. Since 1993, this prospective study has consecutively recruited and surveyed newly diagnosed patients with PCa independently of their family history. Patients are referred by urologists and cooperating clinics throughout Germany. Briefly, the database is updated annually via questionnaires providing information about sociodemographic and clinicopathological data as well as family history. Relatives subsequently diagnosed with $\mathrm{PCa}$ are included in the database. Informed consent is obtained from each patient. The study was approved by the ethical review committee of the Technical University of Munich. More detailed descriptions of the database itself have been provided previously. ${ }^{11,12}$

For the current analysis, the eligibility criteria included 1) RP as the primary treatment and 2) the submission of FCR questionnaires in October 2010 (T1) and October 2019 (T2). The response rate was 63.0\% in 2010 (at the T1 assessment) and 61.7\% in 2019 (at the T2 assessment). A nonresponder analysis in 2010 showed that the 3566 patients who did not return the annual questionnaire $(\mathrm{n}=2544)$ or did not fill out questions on FCR $(\mathrm{n}=1022)$ were older at the survey (72.9 vs 71.6 years; $P<.001)$ and at RP $(64.2$ vs 63.7 years; $P=.001)$ and more often had locally advanced disease $(37.7 \%$ vs $32.5 \%$; $P<.001)$ and biochemical recurrence (BCR; $45.4 \%$ vs $31.0 \%$; $P<.001$ ) in comparison with respondents in $2010(\mathrm{~T} 1 ; \mathrm{n}=6072)$. The dropout analysis in 2019 (at the T2 assessment) showed that the 1502 patients who did not return the annual questionnaire $(n=691)$ or did not fill out questions on FCR $(\mathrm{n}=811)$ differed significantly in their age at the survey $(80.7$ vs 78.4 years; $P<.001)$ and at RP (63.8 vs 62.1 years; $P<.001)$ and more often had locally advanced disease $(31.5 \%$ vs $28.4 \% ; P=.036)$ and BCR between 2010 and 2019 (40.1\% vs 36.9\%; $P=.046)$ in comparison with respondents in 2019 . In addition, depressive symptoms $(7.8 \%$ vs $4.8 \%)$ and anxiety symptoms $(7.7 \%$ vs $4.9 \%)$ in 2010 were more prevalent $(P<.001)$ in nonrespondents in comparison with respondents in 2019 ( $\mathrm{n}=2417)$, but FCR did not differ (mean Fear of Progression QuestionnaireShort Form [FoP-Q-SF] score, 21.7 vs 21.2; $P=.136$; Supporting Table 1). Figure 1 outlines the flow of PCa survivors through the study.

\section{Measures}

\section{Fear of cancer recurrence}

We used the 12-item short version of the Fear of Progression Questionnaire (FoP-Q-SF), which is a validated and reliable instrument to measure fear of disease progression in chronically ill persons as well as FCR in patients with cancer. ${ }^{13,14}$ Items are scored on a 5-point Likert scale ranging from 1 (never) to 5 (very often), with higher values indicating higher levels of fear. High FCR was defined as an FoP-Q-SF total score of 34 or higher. ${ }^{15}$ The Cronbach $\alpha$ values in the current sample were 0.88 and 0.87 in 2010 (T1) and 2019 (T2), respectively.

\section{Sociodemographic characteristics}

Sociodemographic characteristics included age at the survey in 2010 and 2019 ( $\leq 70,<70$ to 80 , or $>80$ years), level of education (low, intermediate, high, or tertiary), partnership (yes vs no), and children (yes vs no).

\section{Clinicopathological characteristics}

Clinicopathological characteristics included age at $\mathrm{RP}(\leq 55,<55$ to 65 , or $>65$ years), years since RP $(\leq 5,<5$ to $10,<10$ to $15,<15$ to 20 , or $>20$ years), prostate-specific antigen (PSA) level at diagnosis (ng/ $\mathrm{mL}$ ), organ-defined disease, positive PCa family history (defined as a patient with at least 1 affected relative with $\mathrm{PCa}$ ), secondary cancer, BCR (defined as a PSA value $\geq 0.2 \mathrm{ng} / \mathrm{mL}$ ) between $\mathrm{RP}$ and 2010 and between 2010 and 2019, and current therapy (radiation, androgen deprivation, and chemotherapy vs none) in 2010 and 2019. Depression and anxiety symptoms were assessed with the Patient Health Questionnaire 4 module, an ultrabrief screening tool consisting of a 2-item depression scale (Patient Health Questionnaire 2 [PHQ-2]) and a 2-item anxiety scale (Generalized Anxiety Disorder 2 [GAD-2]). The German version 


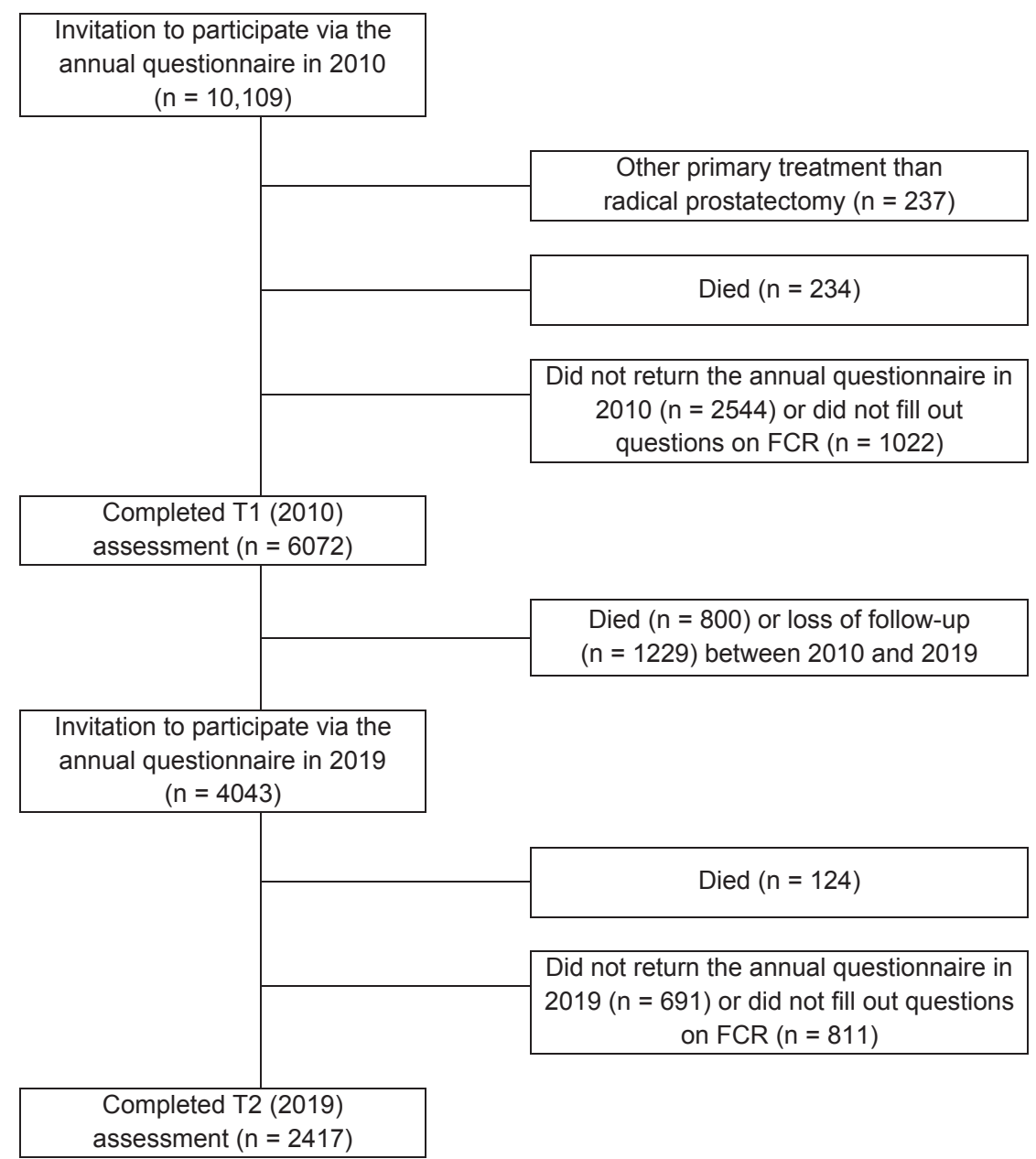

Figure 1. Flowchart of the study design and number of participants. FCR indicates fear of cancer recurrence.

has been proven to be reliable and valid, with a cutoff score $\geq 3$ indicating clinical levels of depression and anxiety. ${ }^{16}$ The Cronbach $\alpha$ coefficients in the current sample were 0.79 and 0.66 for the depression scale and 0.77 and 0.75 for the anxiety scale in 2010 and 2019 , respectively.

\section{Statistical Analysis}

Descriptive statistics calculating counts and percentages for categorical variables and means and standard deviations (SDs) for continuous variables were used to present participant characteristics in 2010 (T1) and in 2019 (T2). In accordance with previous studies, ${ }^{17-19}$ patients were categorized into 4 subgroups based on the cutoff score of our measure: resilient (stable low; low FCR in 2010 and 2019), incident (low FCR in 2010 and high FCR in 2019), recovered (high FCR in 2010 and low
FCR in 2019), and chronic (stable high; high FCR in 2010 and 2019). Group differences were analyzed with $\chi^{2}$ or Fisher exact tests for categorical variables and with analyses of variance or Wilcoxon-Mann-Whitney tests for continuous variables. Hierarchical multivariable logistic regression models were calculated to identify and assess predictors of FCR in 2019 via characteristics available in 2010 (step 1) and via characteristics available in 2019 (step 2). FCR was dichotomized, and clinical FCR was defined as a total FoP-Q-SF score of 34 or higher. In addition to the logistic approach, a linear multivariable regression analysis was conducted as a sensitivity analysis assessing FCR as a continuous variable. Likert-scaled predictors were entered into the regression analyses as continuous variables. All tests were 2 -sided. $P$ values $<.05$ were considered statistically significant. All analyses were performed with SAS 9.4. 
TABLE 1. Sociodemographic, Clinicopathological, and Psychological Characteristics of the Study Population ( $\mathrm{N}=2417)$

\begin{tabular}{|c|c|c|}
\hline & T1 (2010) & T2 (2019) \\
\hline \multicolumn{3}{|l|}{ Sociodemographic characteristics } \\
\hline Age at survey, mean (SD), y & $69.5(5.9)$ & $78.4(5.9)$ \\
\hline \multicolumn{3}{|l|}{ Age at survey, No. (\%) } \\
\hline$\leq 70$ y & $1176(48.7)$ & $221(9.1)$ \\
\hline$>70$ to $80 y$ & $1187(49.1)$ & $1174(48.6)$ \\
\hline$>80 y$ & $54(2.2)$ & $1022(42.3)$ \\
\hline \multicolumn{3}{|l|}{ Level of education, No. (\%) } \\
\hline Low & $928(39.5)$ & \\
\hline Intermediate & $416(17.7)$ & \\
\hline High & $280(11.9)$ & \\
\hline Tertiary & $728(30.9)$ & \\
\hline \multicolumn{3}{|l|}{ Partnership, No. (\%) } \\
\hline Yes & 2256 (94.6) & $2240(92.8)$ \\
\hline No & $129(5.4)$ & $173(7.2)$ \\
\hline \multicolumn{3}{|l|}{ Children, No. (\%) } \\
\hline Yes & $2147(89.0)$ & \\
\hline No & $266(11.0)$ & \\
\hline \multicolumn{3}{|l|}{ Clinicopathological characteristics } \\
\hline Age at RP, mean (SD), y & $62.1(5.9)$ & \\
\hline \multicolumn{3}{|l|}{ Age at RP, No. (\%) } \\
\hline$\leq 50$ y & $298(12.3)$ & \\
\hline$>55$ to $65 y$ & $1314(54.4)$ & \\
\hline$>65 y$ & 805 (33.3) & \\
\hline Years since RP, mean (SD) & $7.3(3.1)$ & $16.3(3.1)$ \\
\hline \multicolumn{3}{|l|}{ Years since RP, No. (\%) } \\
\hline$\leq 5$ & $667(26.6)$ & \\
\hline$>5$ to 10 & $1309(54.2)$ & \\
\hline$>10$ to 15 & $392(16.2)$ & $1030(42.6)$ \\
\hline$>15$ to 20 & $49(2.0)$ & $1099(45.5)$ \\
\hline$>20$ & & $288(11.9)$ \\
\hline PSA at diagnosis, median (IQR), $\mathrm{ng} / \mathrm{mL}$ & $7.3(6.0)$ & \\
\hline \multicolumn{3}{|l|}{ PSA at diagnosis, No. (\%) } \\
\hline$\leq 4 \mathrm{ng} / \mathrm{mL}$ & $218(9.6)$ & \\
\hline$>4$ to $10 \mathrm{ng} / \mathrm{mL}$ & $1353(59.9)$ & \\
\hline$>10 \mathrm{ng} / \mathrm{mL}$ & $688(30.5)$ & \\
\hline \multicolumn{3}{|l|}{ Organ-defined disease, No. (\%) } \\
\hline Yes & $1706(71.7)$ & \\
\hline No & $675(28.3)$ & \\
\hline \multicolumn{3}{|l|}{ Secondary cancer, No. (\%) } \\
\hline Yes & $103(4.3)$ & $331(13.7)$ \\
\hline No & $2314(95.7)$ & 2086 (86.3) \\
\hline \multicolumn{3}{|l|}{ Positive PCa family history, No. (\%) } \\
\hline Yes & $799(33.1)$ & $910(37.6)$ \\
\hline No & $1618(66.9)$ & $1507(62.4)$ \\
\hline \multicolumn{3}{|l|}{$\begin{array}{l}\text { BCR between RP and } 2010 \text { (T1), No. } \\
(\%)\end{array}$} \\
\hline Yes & $610(25.2)$ & - \\
\hline No & $1807(74.8)$ & - \\
\hline \multicolumn{3}{|l|}{$\begin{array}{l}\text { BCR between } 2010 \text { (T1) and } 2019 \text { (T2), } \\
\text { No. (\%) }\end{array}$} \\
\hline Yes & - & $274(12.7)$ \\
\hline No & - & $1890(87.3)$ \\
\hline \multicolumn{3}{|l|}{ Current therapy } \\
\hline Yes & $223(9.2)$ & $318(13.2)$ \\
\hline No & $2194(90.8)$ & $2098(86.8)$ \\
\hline \multicolumn{3}{|l|}{ Psychological characteristics } \\
\hline Fear of cancer recurrence, mean (SD) & $21.2(7.3)$ & $22.2(7.4)$ \\
\hline \multicolumn{3}{|l|}{ Fear of cancer recurrence, No. (\%) } \\
\hline Yes & $156(6.5)$ & $202(8.4)$ \\
\hline No & 2261 (93.5) & 2215 (91.6) \\
\hline Depression, No. (\%) & & \\
\hline Yes & $115(4.8)$ & $336(14.3)$ \\
\hline No & 2259 (95.2) & $2013(85.7)$ \\
\hline
\end{tabular}

TABLE 1. (Continued)

\begin{tabular}{lcc}
\hline & T1 (2010) & T2 (2019) \\
\hline $\begin{array}{c}\text { Anxiety, No. (\%) } \\
\text { Yes }\end{array}$ & $116(4.9)$ & $247(10.6)$ \\
No & $2256(95.1)$ & $2089(89.4)$ \\
\hline $\begin{array}{l}\text { Abbreviations: BCR, biochemical recurrence; IQR, interquartile range; PCa, } \\
\text { prostate cancer; PSA, prostate-specific antigen; RP, radical prostatectomy; }\end{array}$ \\
SD, standard deviation. \\
The presented numbers are from the completed entries and do not always \\
add up to the total sample size. The maximum percentage of missing data \\
is $10.5 \%$.
\end{tabular}

\section{RESULTS}

\section{Characteristics of the Study Population}

Sociodemographic, clinicopathological, and psychological characteristics of the study population of 2417 former RP patients in 2010 (T1) and in 2019 (T2) are presented in Table 1. The mean age at the initial assessment in 2010 was 69.5 years (SD, 5.9 years); $11.9 \%$ had a high level of education, and $30.9 \%$ had a tertiary level of education. The mean time since RP was 7.3 years (SD, 3.1 years) in 2010 and 16.3 years (SD, 3.1 years) in 2019; $25.2 \%$ of the patients had BCR between RP and 2010, and 12.7\% did between 2010 and 2019 .

At the initial assessment in $2010,6.5 \%$ of the patients had high FCR, and this percentage increased to $8.4 \% 9$ years later $(P=.001)$. The average total short form score out of a total of 60 , with higher values indicating greater fear, for the population was $21.2(\mathrm{SD}, 7.3)$ and $22.2(\mathrm{SD}, 7.4)$ in 2010 and 2019, respectively. The prevalences of clinical levels of depression (PHQ-2 score $\geq 3$ ) and anxiety (GAD-2 score $\geq 3$ ) were $4.8 \%$ and $4.9 \%$, respectively, in 2010 and $14.3 \%$ and $10.6 \%$, respectively, in 2019 (Table 1).

As shown in Table 2, most patients (88.4\%) reported low FCR in 2010 (T1) and 2019 (T2; "resilient"), 3.2\% had high FCR at both time points ("chronic"), 5.2\% reported low FCR in 2010 but high FCR in 2019 ("incident"), and 3.2\% had high FCR in 2010 and low FCR in 2019 ("recovered"). Almost two-thirds of the chronic subgroup $(66.2 \%)$ reported a low level of education, whereas one-third $(33.1 \%)$ of the resilient subgroup reported a tertiary level of education $(P<.001)$. Patients in the resilient subgroup more often had organ-defined disease in comparison with patients from the other groups $(P=.012)$. Both depression and anxiety showed the highest prevalence in the chronic subgroup $(P<.001$; Table 2$)$.

\section{Hierarchical Multivariable Logistic Regression Analysis}

To investigate long-term predictors of FCR, patient factors measured in 2010 (T1) were tested for an 
TABLE 2. Distribution of Characteristics Among 4 Patient Subgroups According to Their Fear of Cancer Recurrence Between 2010 and 2019

\begin{tabular}{|c|c|c|c|c|c|}
\hline Characteristic & $\begin{array}{c}\text { Chronic }(n=78 \\
[3.2 \%])\end{array}$ & $\begin{array}{c}\text { Incident }(\mathrm{n}=124 \\
[5.2 \%])\end{array}$ & $\begin{array}{c}\text { Recovered }(n=78 \\
[3.2 \%])\end{array}$ & $\begin{array}{c}\text { Resilient }(n=2137 \\
[88.4 \%])\end{array}$ & $P$ \\
\hline Level of education & & & & & $<.001$ \\
\hline Low & 66.2 & 57.9 & 45.2 & 37.2 & \\
\hline Intermediate & 16.2 & 16.5 & 15.1 & 17.9 & \\
\hline High & 13.5 & 12.4 & 13.7 & 11.8 & \\
\hline Tertiary & 4.1 & 13.2 & 26.0 & 33.1 & \\
\hline \multicolumn{6}{|l|}{ Partnership } \\
\hline In 2010 (T1) & 97.4 & 93.6 & 98.7 & 94.4 & .267 \\
\hline In 2019 (T2) & 96.2 & 91.9 & 98.7 & 92.6 & .101 \\
\hline Children & 92.3 & 93.6 & 94.9 & 88.4 & .069 \\
\hline Age at RP, mean (SD), y & $60.0(6.4)$ & $63.0(5.6)$ & $58.4(6.2)$ & $62.3(5.9)$ & $<.001$ \\
\hline Years since RP, mean (SD) & $7.0(2.8)$ & $7.9(3.4)$ & $6.9(3.0)$ & $7.3(3.1)$ & .167 \\
\hline PSA at diagnosis & & & & & .544 \\
\hline$\leq 4 \mathrm{ng} / \mathrm{mL}$ & 8.0 & 5.2 & 9.7 & 10.0 & \\
\hline$>4$ to $10 \mathrm{ng} / \mathrm{mL}$ & 60.0 & 66.7 & 54.2 & 59.7 & \\
\hline$>10 \mathrm{ng} / \mathrm{mL}$ & 32.0 & 28.1 & 36.1 & 30.3 & \\
\hline Organ-defined disease & 61.5 & 62.3 & 65.3 & 72.7 & .012 \\
\hline \multicolumn{6}{|l|}{ Secondary cancer } \\
\hline In 2010 (T1) & 1.3 & 4.8 & 6.4 & 4.3 & .404 \\
\hline In 2019 (T2) & 14.1 & 16.9 & 14.1 & 13.5 & .751 \\
\hline \multicolumn{6}{|l|}{ Positive PCa family history } \\
\hline In $2010(T 1)$ & 34.6 & 29.8 & 32.1 & 33.2 & .867 \\
\hline In 2019 (T2) & 42.3 & 31.5 & 38.5 & 37.8 & .424 \\
\hline BCR between RP and 2010 (T1) & 39.7 & 42.7 & 37.2 & 23.3 & $<.001$ \\
\hline $\begin{array}{l}\text { BCR between } 2010 \text { (T1) and } \\
2019 \text { (T2) }\end{array}$ & 14.5 & 15.5 & 8.0 & 12.6 & .479 \\
\hline \multicolumn{6}{|l|}{ Current therapy } \\
\hline In 2010 (T1) & 15.4 & 12.9 & 23.1 & 8.3 & $<.001$ \\
\hline In 2019 (T2) & 24.4 & 30.7 & 20.5 & 11.5 & $<.001$ \\
\hline \multicolumn{6}{|l|}{ Depression } \\
\hline In 2010 (T1) & 39.5 & 5.9 & 27.0 & 2.8 & $<.001$ \\
\hline In 2019 (T2) & 48.7 & 44.2 & 31.2 & 10.7 & $<.001$ \\
\hline \multicolumn{6}{|l|}{ Anxiety } \\
\hline In 2010 (T1) & 42.7 & 7.6 & 32.9 & 2.4 & $<.001$ \\
\hline In 2019 (T2) & 42.1 & 42.0 & 20.5 & 7.2 & $<.001$ \\
\hline
\end{tabular}

Abbreviations: BCR, biochemical recurrence PCa, prostate cancer; PSA, prostate-specific antigen; RP, radical prostatectomy; SD, standard deviation.

All numbers are percentages except where indicated.

association with high FCR 9 years later in 2019 (T2) via a multivariable logistic regression including all as main effects (Table 3, step 1). Higher levels of education were strongly associated with a lower risk of FCR (tertiary level of education odds ratio [OR], 0.24; 95\% confidence interval [CI], 0.14-0.41). A higher age at RP (OR, 1.05; 95\% CI, 1.01-1.08) and more years since RP (OR, 1.09; 95\% CI, 1.03-1.15) were both associated with a higher risk of FCR 9 years later. BCR and anxiety between RP and 2010 predicted higher FCR 9 years later (OR for BCR, 1.87; 95\% CI, 1.28-2.71; OR for anxiety, 1.62; 95\% CI, 1.31-2.01; Table 3, step1). High FCR in 2010 was the strongest predictor of FCR in 2019 (OR, 9.31; 95\% CI, 5.70-15.20).

To control for concurrent risk factors in 2019 (T2) in addition to the long-term predictors in 2010 (T1), risk factors measured in 2019 in addition to those measured in 2010 were entered into a second logistic regression model for FCR in 2019. A tertiary level of education remained a strong predictor for low FCR (OR, 0.23; 95\% CI, 0.12-0.43). Age at RP no longer showed an association with a higher risk of FCR when factors at T2 were added. Patients under PCa therapy in 2010 had a lower risk for FCR in 2019 (OR, 0.42; 95\% CI, 0.21-0.84), whereas patients under PCa therapy in 2019 had a nearly 3 times higher risk of high FCR at 2010 (OR, 2.82; 95\% CI, 1.59-5.00). High FCR in 2010 was the strongest predictor of FCR in 2019 (OR, 10.75; 95\% CI, 6.18-18.72). Anxiety in 2010 (OR, 1.35; 95\% CI, 1.06-1.72) and 2019 (OR, 1.69; $95 \% \mathrm{CI}, 1.37-2.09)$ was associated with higher FCR in 2019. Depression in 2010 was not associated with FCR in 2019 (OR, 0.82; 95\% CI, 0.63-1.06), but depression in 2019 was associated with a higher risk of FCR in 2019 (OR, 1.45; 95\% CI, 1.19-1.78; Table 3).

Results of the additional linear regression analysis, which was conducted as a sensitivity analysis, largely confirmed previous results. In particular, those variables with 
TABLE 3. Hierarchical Multivariable Logistic Regression Analysis to Test for FCR at T2

\begin{tabular}{|c|c|c|c|c|c|c|}
\hline & \multicolumn{3}{|c|}{ Step 1} & \multicolumn{3}{|c|}{ Step 2} \\
\hline & OR & $95 \% \mathrm{Cl}$ & $P$ & OR & $95 \% \mathrm{Cl}$ & $P$ \\
\hline $\begin{array}{l}\text { Level of education (reference: } \\
\text { low) }\end{array}$ & & & $<.001$ & & & $<.001$ \\
\hline Intermediate & 0.75 & $0.48-1.19$ & & 0.65 & $0.37-1.12$ & \\
\hline High & 0.62 & $0.37-1.05$ & & 0.56 & $0.31-1.01$ & \\
\hline Tertiary & 0.24 & $0.14-0.41$ & & 0.23 & $0.12-0.43$ & \\
\hline Age at $\mathrm{RP}^{\mathrm{a}}$ & 1.05 & $1.01-1.08$ & .004 & 1.02 & $0.99-1.06$ & .228 \\
\hline $\mathrm{T} 1$ : years since $\mathrm{RP}^{\mathrm{a}}$ & 1.09 & $1.03-1.15$ & .005 & 1.10 & $1.03-1.18$ & .006 \\
\hline $\begin{array}{l}\text { T1: secondary cancer (reference: } \\
\text { no) }\end{array}$ & 0.81 & $0.34-1.93$ & .628 & 0.47 & $0.14-1.62$ & .234 \\
\hline $\begin{array}{l}\text { T1: PCa family history (refer- } \\
\text { ence: no) }\end{array}$ & 1.04 & $0.72-1.51$ & .837 & 0.49 & $0.16-1.46$ & .199 \\
\hline $\begin{array}{l}\text { BCR between RP and T1 (refer- } \\
\text { ence: no) }\end{array}$ & 1.87 & $1.28-2.71$ & .001 & 1.67 & $1.02-2.72$ & .040 \\
\hline $\begin{array}{l}\text { T1: current therapy (reference: } \\
\text { no) }\end{array}$ & 0.81 & $0.47-1.41$ & .460 & 0.42 & $0.21-0.84$ & .015 \\
\hline T1: FCR (reference: no) & 9.31 & $5.70-15.20$ & $<.001$ & 10.75 & $6.18-18.72$ & $<.001$ \\
\hline T1: depression ${ }^{\mathrm{a}}$ & 1.00 & $0.80-1.25$ & .996 & 0.82 & $0.63-1.06$ & .123 \\
\hline T1: anxiety $^{\mathrm{a}}$ & 1.62 & $1.31-2.01$ & $<.001$ & 1.35 & $1.06-1.72$ & .015 \\
\hline $\begin{array}{l}\text { T2: secondary cancer (reference: } \\
\text { no) }\end{array}$ & & & & 1.11 & $0.59-2.10$ & .758 \\
\hline $\begin{array}{l}\text { T2: PCa family history (refer- } \\
\text { ence: no) }\end{array}$ & & & & 2.24 & $0.77-6.50$ & .140 \\
\hline $\begin{array}{l}\text { BCR between T1 and T2 (refer- } \\
\text { ence: no) }\end{array}$ & & & & 1.57 & $0.86-2.86$ & .139 \\
\hline $\begin{array}{l}\text { T2: current therapy (reference: } \\
\text { no) }\end{array}$ & & & & 2.82 & $1.59-5.00$ & $<.001$ \\
\hline T2: depression ${ }^{\mathrm{a}}$ & & & & 1.45 & $1.19-1.78$ & $<.001$ \\
\hline T2: anxiety ${ }^{a}$ & & & & 1.69 & $1.37-2.09$ & $<.001$ \\
\hline
\end{tabular}

Abbreviations: BCR, biochemical recurrence; Cl, confidence interval; FCR, fear of cancer recurrence; OR, odds ratio; PCa, prostate cancer; RP, radical prostatectomy. ${ }^{\mathrm{a}}$ Variables were entered continuously.

higher ORs in the logistic regression analysis were confirmed by the linear approach. In contrast to the main analysis, BCR between 2010 and 2019 was associated with higher FCR in 2019 in the linear regression analysis $(\beta=0.045 ; P=.006$; Supporting Table 2$)$.

\section{DISCUSSION}

The primary objectives of the current study were to assess the prevalence and evaluate the trajectory of FCR in longterm PCa survivors and to identify predictors of FCR. After a mean time of 7.3 years $(2010$; T1) after diagnosis and treatment, $6.5 \%$ of the survivors reported high levels of FCR. In 2019 (T2), approximately 9 years later, 8.4\% of the survivors reported high FCR; this suggested that FCR increased slightly over time. A hierarchical multivariable logistic regression analysis revealed several factors in 2010, such as level of education, BCR in the first years after treatment, years since RP, current therapy, FCR, and anxiety, to be important predictors of FCR approximately 9 years later in long-term PCa survivors.

The main results of the current study showed that high FCR in 2010 was the strongest predictor and was associated with a 10 -fold increase in the odds of having FCR 9 years later. Therefore, patients should be monitored for FCR early after treatment to identify those at risk and start early psychological interventions; this underlines the clinical implications of the results of the current study. A recent review and meta-analysis of the effect of psychological interventions showed that cognitive behavioral therapies were effective in reducing FCR, with effects maintained at follow-up. ${ }^{20}$

In the current analysis, the prevalence of FCR $(6.5 \%$ in 2010 and $8.4 \%$ in 2019) was lower than rates reported in previous studies. For instance, using the same validated FoP-Q-SF cutoff score, Hinz et $\mathrm{al}^{14}$ reported that $16.7 \%$ of patients with cancer scored high levels of FCR 6 months after their diagnosis. Recently, using the aforementioned cutoff score, Götze et $\mathrm{al}^{21}$ reported similar rates in longterm cancer survivors. In a 5-year cohort, $19 \%$ of the cancer survivors showed high levels of FCR, and 13\% did so in a 10 -year cohort. However, it is noteworthy that both samples were not restricted to homogeneous subgroups of cancer types. It is well established that the prevalence of FCR is higher in patients with breast, lung, or ovarian cancer than patients with $\mathrm{PCa}{ }^{22}$ Similarly, the 
mean FoP-Q-SF scores of the current analysis (21.2 in 2010 [T1] and 22.2 in 2019 [T2]) were lower than the mean scores reported in the previous studies of Hinz et al (24.9) and Götze et al (25.1 [5-year cohort] and 23.7 $\left[10\right.$-year cohort]). In a prospective study, Mehnert et $\mathrm{al}^{23}$ reported that at the beginning of cancer rehabilitation, on average 11 months after diagnosis, approximately $18 \%$ of patients with cancer reported high FCR. After 1 year, this rate remained almost stable, and $17 \%$ still had high levels of FCR. However, the prevalence rates and severity of FCR must be interpreted with caution because FCR is usually not experienced constantly and can be triggered by specific situations, such as clinical check-ups or environmental triggers (eg, television or internet). ${ }^{24}$

Confirming previous research, we observed a strong association between a lower educational level and higher FCR. ${ }^{22,25,26}$ The link between level of education and FCR possibly might be due to a better understanding of the disease, more effective coping strategies, or higher standards of living.

In step 1 of the hierarchical multivariable logistic regression analysis, a higher age at RP was associated with higher FCR in 2019. However, this observed effect disappeared when factors of 2019 (T2) were added in step 2. A meta-analysis by Simard et $\mathrm{al}^{22}$ showed strong evidence that younger age is a consistent predictor of high FCR. However, a closer look revealed that studies showing no significant relationship were mainly investigating samples comprising men (eg, testicular cancer and PCa), ${ }^{22}$ and this is in line with our findings. Reasons that younger men may be more vulnerable to FCR include the unexpectedness of cancer and the fact that a diagnosis poses a threat to important life projects such as marriage, having children, and building careers. ${ }^{27}$ PCa survivors of the current analysis were approximately 70 years old in 2010 and 79 years old in 2019; therefore, marriage, having children, and building careers might not be relevant factors anymore in their life, and this partly explains the lack of correlation.

A positive family history of $\mathrm{PCa}$ and secondary cancers of the patients were both unrelated to FCR among PCa survivors in the current analysis. This finding is in line with previous research. ${ }^{22,28}$ Although a positive family history is a well-known risk factor for developing PCa, it is not associated with worse long-term outcomes for PCa survivors. ${ }^{29}$

FCR, however, is present not just in cancer survivors. Partners of patients and family caregivers are also affected by concerns about cancer recurrence. For instance, higher FCR predicted a higher likelihood of PCa screening maintenance among male caregivers. ${ }^{30}$ In a longitudinal study investigating the trajectory of FCR from pretreatment to 1 year later in patients with $\mathrm{PCa}$ and their spouses, spouses experienced even greater FCR than patients with PCa over time. ${ }^{31}$

Results of the current study revealed interesting findings concerning the role of BCR. BCR between RP and the first assessment in 2010 was associated with higher FCR. This is consistent with most studies in which recurrence or metastatic diagnosis was significantly associated with FCR. ${ }^{22,32}$ Late BCR between the first assessment (mean time since RP, 7.3 years) and the second assessment (mean time since RP, 16.3 years) was not associated with higher FCR in the logistic regression analysis. Interestingly, in the linear regression analysis, late BCR was associated with higher FCR. To our knowledge, the current study is the first study investigating the influence of recurrence on FCR in long-term survivors with such a long follow-up. Apparently, indicators of illness severity such as BCR might be losing weight through the survivorship trajectory; however, it is not clear yet to what extent.

Currently receiving therapy (ie, chemotherapy, radiation therapy, or androgen deprivation therapy) in 2019 was associated with almost 3-fold higher odds of FCR. In line with earlier studies, having chemotherapy was associated with higher FCR. ${ }^{22,25,28,33}$ Likewise, evidence was observed between radiotherapy and FCR ${ }^{22,28,34,35}$ and between hormone therapy and FCR. ${ }^{21}$ Interestingly, among survivors of the current study, receiving therapy in 2010 was associated with an even lower risk of FCR 9 years later. A possible explanation for this finding is that having experienced cancer recurrence with a consecutive treatment many years before might lead to the feeling that the treatment was successful and that a new cancer recurrence could be treated the same way.

Depression and anxiety in 2019 were both associated with higher FCR. FCR has continuously been described in the literature as being associated with depression and anxiety, although a causal direction of the relationship is unknown. ${ }^{36,37}$ Furthermore, there is evidence that intrusive thoughts, hypochondriasis, symptom distress, or posttraumatic stress disorder is likewise associated with FCR, ${ }^{21}$ and this makes FCR the result of different interpretations and cognitions of the threat of cancer.

To date, the current study is the largest registry study assessing the prevalence and predictors of FCR longitudinally over a mean follow-up period of approximately 9 years. This provides information on the perseverance over time of FCR in a representative group of PCa survivors 
treated with RP. The fact that we included only patients after RP indicates very rigorous patient selection; however, it allows excellent comparability and precise factor evaluation.

Nevertheless, our study is not devoid of limitations. First, PCa survivors were treated with RP and hence are not representative of all PCa survivors as a result of selection bias. Second, data for the main outcome measures were self-reported and at risk for exaggeration and misrepresentation, and they may have been affected by social desirability reactions. Third, there was a notable number of PCa survivors who were lost to follow-up or did not answer questions on FCR (Fig. 1). These long-term survivors were noncompliant and could have contributed to nonrandom missing data because they may have had greater FCR than those analyzed in the study. Fourth, although the current study was conducted in Germany and some unique cultural aspects might differ in comparison with $\mathrm{PCa}$ survivors from other countries, there is currently no evidence that this could influence the experience of FCR in a significant manner. However, other health care systems differ considerably from the German system; these differences may include higher uninsured rates or economic and racial/ethnic disparities leading to unequal access to health and cancer care. ${ }^{38}$ Therefore, the results of the current study have to be interpreted with caution and might not be applicable to men with hampered access to health care.

In conclusion, the results of the current study illustrate that FCR is a burden that is still present in some PCa survivors even many years after their diagnosis and treatment. FCR was the strongest predictor of FCR 9 years later. Early monitoring for FCR and the identification of patients at risk are crucial for starting early psychological interventions. A lower level of education, years since RP, BCR in the first years after treatment, no current adjuvant therapy, and anxiety symptoms were further important predictors of FCR in these patients. Therefore, treating health care professionals should be aware of these factors in clinical practice to provide appropriate psychosocial care when needed because FCR is among the most endorsed unmet needs and concerns in cancer survivors leading to limitations in their QOL and psychological well-being.

\section{FUNDING SUPPORT}

No specific funding was disclosed.

\section{CONFLICT OF INTEREST DISCLOSURES}

The authors made no disclosures.

\section{AUTHOR CONTRIBUTIONS}

Valentin H. Meissner: Conception and design of the study; interpretation of the data; administrative, technical, or material support; drafting of the manuscript; and revision of the manuscript for important intellectual content. Lisa Olze: Interpretation of the data, acquisition of the data, and revision of the manuscript for important intellectual content. Stefan Schiele: Statistical analysis; administrative, technical, or material support; and revision of the manuscript for important intellectual content. Donna P. Ankerst: Statistical analysis; interpretation of the data; administrative, technical, or material support; and revision of the manuscript for important intellectual content. Matthias Jahnen: Interpretation of the data and revision of the manuscript for important intellectual content. Jürgen $\mathbf{E}$. Gschwend: Study supervision; administrative, technical, or material support; and revision of the manuscript for important intellectual content. Kathleen Herkommer: Conception and design of the study, development of methodology, acquisition of the data, study supervision, and revision of the manuscript for important intellectual content. Andreas Dinkel: Conception and design of the study, development of methodology, interpretation of the data, drafting of the manuscript, and revision of the manuscript for important intellectual content.

\section{REFERENCES}

1. Henley SJ, Ward EM, Scott S, et al. Annual report to the nation on the status of cancer, part I: national cancer statistics. Cancer. 2020;126:2225-2249.

2. Siegel RL, Miller KD, Jemal A. Cancer statistics, 2019. CA Cancer J Clin. 2019;69:7-34.

3. Armes J, Crowe M, Colbourne L, et al. Patients'supportive care needs beyond the end of cancer treatment: a prospective, longitudinal survey. J Clin Oncol. 2009;27:6172-6179.

4. Dinkel A, Herschbach P. Fear of progression in cancer patients and survivors. Recent Results Cancer Res. 2018;210:13-33.

5. Dinkel A, Kremsreiter K, Marten-Mittag B, Lahmann C. Comorbidity of fear of progression and anxiety disorders in cancer patients. Gen Hosp Psychiatry. 2014;36:613-619.

6. Lebel S, Ozakinci G, Humphris G, et al. From normal response to clinical problem: definition and clinical features of fear of cancer recurrence. Support Care Cancer. 2016;24:3265-3268.

7. Reed SC, Bell JF, Miglioretti DL, Nekhlyudov L, Fairman N, Joseph JG. Relationships between fear of cancer recurrence and lifestyle factors among cancer survivors. J Cancer Educ. 2020;35:669-677.

8. Séguin Leclair C, Lebel S, Westmaas JL. The relationship between fear of cancer recurrence and health behaviors: a nationwide longitudinal study of cancer survivors. Health Psychol. 2019;38:596-605.

9. Mehta SS, Lubeck D, Pasta DJ, Litwin MS. Fear of cancer recurrence in patients undergoing definitive treatment for prostate cancer: results from CaPSURE. J Urol. 2003;170:1931-1933.

10. van de Wal M, van Oort I, Schouten J, Thewes B, Gielissen M, Prins J. Fear of cancer recurrence in prostate cancer survivors. Acta Oncol. 2016;55:821-827.

11. Meissner VH, Strüh JGH, Kron M, et al. The role of fatal family history and mode of inheritance in prostate cancer for long-term outcomes following radical prostatectomy. World J Urol. 2020;38:3091-3099.

12. Paiss T, Herkommer K, Chab A, et al. Familial prostate carcinoma in Germany. Article in German. Urologe A. 2002;41:38-43.

13. Herschbach P, Berg P, Dankert A, et al. Fear of progression in chronic diseases: psychometric properties of the Fear of Progression Questionnaire. J Psychosom Res. 2005;58:505-511.

14. Hinz A, Mehnert A, Ernst J, Herschbach P, Schulte T. Fear of progression in patients 6 months after cancer rehabilitation-a validation study of the Fear of Progression Questionnaire FoP-Q-12. Support Care Cancer. 2015;23:1579-1587.

15. Sarkar S, Scherwath A, Schirmer L, et al. Fear of recurrence and its impact on quality of life in patients with hematological cancers in the course of allogeneic hematopoietic SCT. Bone Marrow Transplant. 2014;49:1217-1222.

16. Löwe B, Wahl I, Rose M, et al. A 4-item measure of depression and anxiety: validation and standardization of the Patient Health Questionnaire-4 (PHQ-4) in the general population. I Affect Disord. 2010;122:86-95. 
17. Lotfi-Jam K, Gough K, Schofield P, et al. A longitudinal study of four unique trajectories of psychological distress in cancer survivors after completing potentially curative treatment. Acta Oncol. 2019;58:782-789.

18. Zebrack BJ, Corbett V, Embry L, et al. Psychological distress and unsatisfied need for psychosocial support in adolescent and young adult cancer patients during the first year following diagnosis. Psychooncology. 2014;23:1267-1275.

19. Ng HJ, Tan WJ, Mooppil N, et al. Prevalence and patterns of depression and anxiety in hemodialysis patients: a 12-month prospective study on incident and prevalent populations. Br J Health Psychol. 2015;20:374-395.

20. Tauber NM, O'Toole MS, Dinkel A, et al. Effect of psychological intervention on fear of cancer recurrence: a systematic review and metaanalysis. J Clin Oncol. 2019;37:2899-2915.

21. Götze H, Taubenheim S, Dietz A, Lordick F, Mehnert-Theuerkauf A. Fear of cancer recurrence across the survivorship trajectory: results from a survey of adult long-term cancer survivors. Psychooncology. 2019;28:2033-2041.

22. Simard S, Thewes B, Humphris G, et al. Fear of cancer recurrence in adult cancer survivors: a systematic review of quantitative studies. $J$ Cancer Surviv. 2013;7:300-322.

23. Mehnert A, Koch U, Sundermann C, Dinkel A. Predictors of fear of recurrence in patients one year after cancer rehabilitation: a prospective study. Acta Oncol. 2013;52:1102-1109.

24. Lee-Jones C, Humphris G, Dixon R, Hatcher MB. Fear of cancer recurrence - a literature review and proposed cognitive formulation to explain exacerbation of recurrence fears. Psychooncology. 1997;6:95-105.

25. Costanzo ES, Lutgendorf SK, Mattes ML, et al. Adjusting to life after treatment: distress and quality of life following treatment for breast cancer. Br J Cancer. 2007;97:1625-1631.

26. Skaali T, Fosså SD, Bremnes R, et al. Fear of recurrence in long-term testicular cancer survivors. Psychooncology. 2009;18:580-588.

27. Chambers SK, Lowe A, Hyde MK, et al. Defining young in the context of prostate cancer. Am J Mens Health. 2015;9:103-114.

28. Janz NK, Hawley ST, Mujahid MS, et al. Correlates of worry about recurrence in a multiethnic population-based sample of women with breast cancer. Cancer. 2011;117:1827-1836.
29. Brath JM, Grill S, Ankerst DP, Thompson IM Jr, Gschwend JE, Herkommer K. No detrimental effect of a positive family history on long-term outcomes following radical prostatectomy. J Urol. 2016;195:343-348.

30. Takeuchi E, Kim Y, Shaffer KM, Cannady RS, Carver CS. Fear of cancer recurrence promotes cancer screening behaviors among family caregivers of cancer survivors. Cancer. 2020;126:1784-1792.

31. Wu LM, McGinty H, Amidi A, Bovbjerg K, Diefenbach MA. Longitudinal dyadic associations of fear of cancer recurrence and the impact of treatment in prostate cancer patients and their spouses. Acta Oncol. 2019;58:708-714.

32. Ullrich PM, Carson MR, Lutgendorf SK, Williams RD. Cancer fear and mood disturbance after radical prostatectomy: consequences of biochemical evidence of recurrence. J Urol. 2003;169: 1449-1452.

33. Mehnert A, Berg P, Henrich G, Herschbach P. Fear of cancer progression and cancer-related intrusive cognitions in breast cancer survivors. Psychooncology. 2009;18:1273-1280.

34. Hong YM, Hu JC, Paciorek AT, Knight SJ, Carroll PR. Impact of radical prostatectomy positive surgical margins on fear of cancer recurrence: results from CaPSURE. Urol Oncol. 2010;28:268-273.

35. Bergman J, Gore JL, Saigal CS, Kwan L, Litwin MS. Partnership and outcomes in men with prostate cancer. Cancer. 2009;115: 4688-4694.

36. Deimling GT, Bowman KF, Sterns S, Wagner LJ, Kahana B. Cancerrelated health worries and psychological distress among older adult, long-term cancer survivors. Psychooncology. 2006;15:306-320.

37. Liu J, Peh CX, Simard S, Griva K, Mahendran R. Beyond the fear that lingers: the interaction between fear of cancer recurrence and rumination in relation to depression and anxiety symptoms. J Psychosom Res. 2018;111:120-126.

38. Mossialos E, Djordjevic A, Osborn R, Sarnak D. International Profiles of Health Care Systems. Commonwealth Fund. Published May 2017. Accessed March 15, 2021. https://www.commonwealthfund.org/ sites/default/files/documents/__media_files_publications_fund_report_2017_may_mossialos_intl_profiles_v5.pdf 